\title{
Influência da formação na prática de professores de Educação Física que atuam com alunos com deficiência: um estudo no sistema de ensino especial ${ }^{1}$
}

\author{
Marcelo de Melo Mendes ${ }^{2}$ \\ marcelogab2@yahoo.com.br \\ Karla Cunha Pádua ${ }^{3}$ \\ kcpadua@yahoo.com.br
}

\begin{abstract}
Resumo
Neste artigo sintetiza-se parte dos resultados de uma pesquisa para identificar influências da formação na prática de professores de Educação Física que atuam com alunos com deficiência no ensino especial. A pesquisa contou com a participação de quatro professores de Educação Física de três escolas públicas do ensino especial, administradas pelo Estado de Minas Gerais e localizadas em Belo Horizonte. Os dados foram coletados por meio de entrevistas semiestruturadas, observação participante das práticas docentes e análise de documentos. Pelos resultados verificouse que, apesar dos avanços conquistados, ainda há muito a se fazer para a melhoria da formação inicial e continuada de professores, tendo em vista uma educação comprometida com a diversidade e com a inclusão de todos, em especial, dos alunos com deficiência.
\end{abstract}

1 Este trabalho é parte da dissertação de mestrado do primeiro autor, apresentado na Universidade Vale do Rio Verde de Três Corações, sob a orientação do segundo autor.

2 Mestre em Educação, analista de Políticas Públicas da Secretaria Municipal Adjunta de Esportes, professor da Universidade FUMEC e Faculdade Pitágoras/Betim.

3 Doutora em Educação e professora da Faculdade de Educação da Universidade do Estado de Minas Gerais.

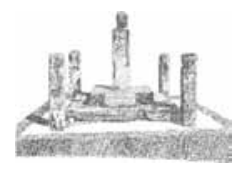

Ano 13 - n. 16 - dezembro 2010 - p. 13-39 
Nessa direção, no estudo foram indicadas potencialidades formativas dos saberes adquiridos nas experiências diretas com alunos deficientes e nas redes de troca e de apoio com profissionais mais experientes.

Palavras-chave: Educação Física; formação de professores; alunos com deficiência; ensino especial.

\section{Introdução}

O trabalho dos professores de Educação Física com alunos com deficiência se insere hoje num contexto mundial de conquistas legislativas que garantiram uma série de direitos às pessoas com deficiência, principalmente nas instâncias da profissão, saúde, educação, lazer, moradia e acessibilidade.

No Brasil, o marco dessas conquistas foi a Constituição Federal de 1988 e outros decretos e diretrizes de leis que surgiram a partir de recomendações de importantes conferências internacionais. Entre tais conferências internacionais, as mais significativas foram a Declaração Mundial sobre Educação para Todos (UNESCO, 1990), aprovada pela Conferência Mundial sobre Educação para Todos, realizada em Jomtien, Tailândia, no ano de 1990; a Declaração de Salamanca (UNESCO, 1994), firmada na Espanha em 1994; a Convenção interamericana voltada para a eliminação de toda forma de discriminação contra a pessoa com deficiência, na Guatemala, em 1999 e a Declaração Internacional de Montreal sobre a inclusão, em 2001, que marcaram pontos favoráveis e determinantes como políticas de inclusão da pessoa com deficiência na educação.

Para Mantoan (2006), o termo inclusão é uma provocação. Provocação que tem a intenção de melhorar a qualidade do ensino das escolas. O objetivo da inclusão é possibilitar o acesso, a permanência na escola e o sucesso acadêmico de todos os alunos. Para esse acesso à escola, no Brasil coexistem dois sistemas: o ensino regular comum e o ensino especial. De acordo com perspectivas 
de parâmetros legais e autores como Mantoan (2006, 2008), Batista (2004), Carvalho (1998, 2007), Sassaki (2007) e Werneck (1993, 1999), o sistema de ensino regular comum deveria ser transformado de tal forma que, a partir do momento em que a escola fosse inclusiva, todos os alunos, independentemente de suas condições peculiares, estivessem inseridos juntos num mesmo estabelecimento de ensino. Nesses pressupostos, propõe-se o fim do ensino especial.

Entretanto, apesar de movimentos contrários, a escola de ensino especial persiste em existir. Isso se dá em função de diversos fatores, tais como a necessidade de atendimentos especializados a determinados alunos com deficiência, a presença de alunos com dificuldades de aprendizagem no ensino regular que utilizam das salas de recursos em escolas especiais e a presença de professores especialistas que se capacitam e se formam para atuar com determinado tipo de público. Nesse sentido, Muller e Glat (2007, p. 17) defendem que,

[...] é nossa firme convicção que a classe especial tem sua função e clientela específica e que, pelo menos em nosso país, ainda perdurará como modalidade de ensino por muito tempo. Em outras palavras, consideramos que a classe especial é para muitos alunos a melhor opção de aprendizagem, principalmente para aqueles que ainda não têm (ou que provavelmente não terão jamais) condições de freqüentar (sic) com aproveitamento acadêmico a classe regular. Mas, certamente, para que possa atender às demandas sócio-educacionais (sic) atuais, ela necessita urgentemente de uma transformação.

Na perspectiva dessas autoras, assim como no sistema de ensino comum regular, a escola especial também necessita ser transformada para melhor qualificação do ensino. Mas essa transformação das práticas pedagógicas da classe especial não pode ocorrer por intermédio de um modelo externo, determinado de fora para dentro, mas pelos próprios professores.

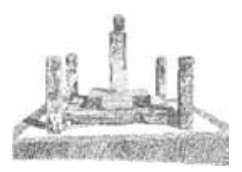


No entanto, apesar das legislações e propostas relativas à inclusão das pessoas com deficiência, inúmeras barreiras dificultam o estabelecimento de políticas na prática cotidiana das escolas brasileiras. Entre essas barreiras, destacamos o despreparo dos profissionais da área de educação para atuar com alunos "problemas", entre eles os deficientes (BUENO, 2004). Partimos do pressuposto de que esse despreparo, ou "necessidade de capacitação", termo bastante utilizado por profissionais da educação quando apresentam dificuldades em atuar com alunos com deficiências, poderia ser minimizado com investimentos nas formações iniciais e continuadas do professor. Além disso, acreditamos que há outras influências de caráter pessoal e da história de vida do profissional, assim como elementos da trajetória de formação inicial e continuada, que interferem na configuração das concepções e práticas de atuação dos professores de Educação Física com alunos com deficiência.

É preciso considerar que os percursos formativos dos professores estão em constante construção e são constituídos por diversas dimensões, sejam pessoais, profissionais, acadêmicas, sociais, culturais e históricas. Essa construção formativa não acontece de forma solitária e nem descontextualizada de aspectos culturais e sócio-históricos, mas por meio de uma reflexão do próprio profissional, com trocas de experiências entre seus pares e conhecimentos adquiridos nas práticas sociais, docentes e de formação. O processo de formação é carregado de sonhos, intenções, valores e contradições relacionados a sentidos e experiências que tocam o sujeito (LARROSA, 2002).

A partir da atribuição da Educação Física de desenvolver trabalhos com deficientes, pelo Conselho Federal de Educação em 1987, as escolas de ensino superior inseriram no curso de Educação Física disciplinas que abordam a atividade física para pessoas com deficiência (PEDRINELLI, 2005). Passou a ser uma preocupação e um questionamento das instituições de ensino superior a questão de como formar o profissional de Educação Física, na graduação, 
para atuar com alunos com deficiência.

Na prática, antes mesmo da inserção de disciplinas que abordassem atividade física para pessoas com deficiência, o profissional já atuava com esses alunos. Para isso, utilizava conhecimentos adquiridos na própria prática ou vindos da formação continuada, o que dependia do interesse e da motivação do docente. Atualmente é uma determinação da própria Constituição Federal e da Leis de Diretrizes e Bases da Educação que os profissionais de licenciatura tenham em seu currículo disciplinas que discutam e abordem o tema "pessoas portadoras de necessidades especiais" ou "pessoas com deficiência".

Portanto, não é mais uma escolha do profissional a questão de se trabalhar com o deficiente ou não; a "escola para todos" obriga o profissional a se capacitar. As políticas de inclusão exigem que os futuros profissionais se formem para atuar com alunos diferentes e com condições peculiares, independentemente de seu desejo. Nessa perspectiva, propusemos estudar as influências da formação nas práticas dos profissionais de Educação Física que atuam com deficientes, seja essa formação de caráter pessoal, inicial ou continuada.

Para compreender os resultados desse estudo, serão apresentadas, a seguir, uma contextualização da pesquisa realizada e a metodologia utilizada.

\section{Contextualizando a pesquisa}

Com o propósito de analisar a influência da formação pessoal, inicial e continuada na prática de professores de Educação Física com alunos com deficiência, buscamos traçar um itinerário de pesquisa baseado em pressupostos que norteiam a pesquisa qualitativa. Além disso, buscou-se uma fundamentação teórica, realizada a partir de uma revisão de bibliografia sobre a temática estudada, que teve o papel de ajudar a situar e compreender o campo da pesquisa, isto é, conhecer o movimento de construção

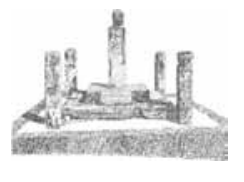


histórica das políticas de Educação Física no Brasil e das propostas educacionais voltadas às pessoas com deficiência.

Quanto ao trabalho de campo, selecionamos quatro professores formados em licenciatura em Educação Física que atuam em escolas estaduais do sistema de ensino especial, localizadas em Belo Horizonte. A escolha das escolas se deu durante a fase exploratória da pesquisa, na qual foram realizadas visitas às oito escolas estaduais do sistema de ensino especial do estado de Minas Gerais existentes em Belo Horizonte e pela observação de aulas de professores de Educação Física.

Essa fase exploratória norteou a seleção de três escolas que atuam com públicos diferenciados: uma que trabalha com alunos com deficiência visual e múltipla, outra que atua com alunos com deficiência auditiva e múltipla e uma escola que lida com alunos com deficiência intelectual e múltipla. Nessas escolas selecionamos quatro professores com até seis anos de formação em licenciatura em Educação Física e que haviam estudado em diferentes instituições de ensino superior para a realização das entrevistas semiestruturadas.

Todas as entrevistas foram realizadas nas próprias escolas onde os professores trabalhavam, em locais disponíveis no momento da coleta de informações, como sala da diretora, pátio, área externa e sala dos professores. Em todos esses ambientes não ocorreram interferências que atrapalhassem a condução das entrevistas, que foram gravadas e armazenadas em um equipamento de gravadorreprodutor "Sony MP3" e posteriormente transcritas.

Após a transcrição, os dados coletados nas entrevistas foram submetidos à análise de conteúdo e complementados com a análise de documentos e das anotações da observação participante de aulas de Educação Física, realizadas uma vez por semana com cada um dos professores no decorrer do primeiro semestre de 2010. Conforme Bardin (1977) e Franco (2008), a análise de conteúdo aplica-se a discursos e baseia-se na dedução ou inferência sistemática, de forma objetiva, identificando algumas 
características da mensagem por meio da construção de categorias, reunidas por temas de significação.

Assim, de posse de leituras das entrevistas transcritas, das observações das aulas e de referencial teórico foram estabelecidas categorias relacionadas às práticas profissionais e à formação do professor. Em relação às práticas profissionais, foram construídas as categorias "concepções de Educação Física", "dificuldades encontradas na prática", "trajetória de encontro da prática profissional com deficientes" e "o professor de Educação Física e a inclusão de deficientes". No caso da formação profissional, foram construídas as categorias "experiências com deficientes", "formação inicial" e "formação continuada".

Foi realizada a análise de cada uma dessas categorias por professor e, depois, dos quatro professores participantes da pesquisa. $\mathrm{O}$ entrecruzamento das informações possibilitou estabelecer as influências da formação nas práticas dos professores de Educação Física que atuam com alunos com deficiência. É preciso ainda mencionar que a pesquisa bibliográfica e documental permitiu montar uma lente interpretativa, fundamental para a compreensão dos dados empíricos coletados, tanto por meio das entrevistas quanto pelas observações da prática desses profissionais nas escolas.

Para resguardar os professores pesquisados, optamos por não divulgar os seus nomes reais e utilizar os seguintes nomes fictícios: Deanne, Lúcia, Daniele e Tenório, em homenagem aos atletas de judô, deficientes visuais, medalhistas na paraolimpíada de Pequim.

Apresentamos a seguir os principais dados coletados na pesquisa, tecendo a análise a partir de referenciais teóricos que tratam do tema da formação de educadores. Para fins desta apresentação, os resultados do estudo foram separados em três temas: a trajetória de encontro com a prática profissional com deficientes, as concepções e práticas de Educação Física no ensino especial e o olhar dos profissionais sobre a inclusão.

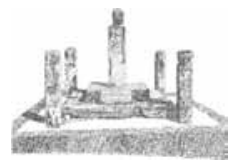




\section{Trajetória de encontro com a prática profissional com deficientes}

Partindo da formação pessoal, os professores pesquisados não relataram nenhuma influência pessoal significativa, antes da graduação em Educação Física, que tivesse interferido no direcionamento do trabalho com pessoas com deficiência. Esse dado encontra-se em desacordo com autores como Mantoan (2006, 2008), Pedrinelli (2005) e Muller e Glat (2007), que citam influências pessoais e familiares para a escolha de se trabalhar com o público formado por pessoas com deficiência.

Além disso, para esses professores, a influência da vida escolar, referindo-se ao ensino fundamental e médio, não auxiliou em suas produções do saber docente para atuar com deficientes, como é defendido por Tardif (2002). Esse fato pode estar relacionado ao contexto social e político da época em que frequentaram tais níveis de ensino, período em que havia pequena presença de alunos deficientes nas escolas, raros debates na sociedade a respeito da inclusão e pouca discussão sobre a potencialidade da prática de Educação Física para alunos com deficiência.

A professora Lúcia comenta que o único contato que teve na infância com deficientes foi com alunos com Síndrome de Down; no entanto, esses contatos teriam se dado de forma bastante superficial, tendo em vista que, como relata, "não era comum ver alunos com deficiência frequentando a sociedade; os próprios familiares escondiam os deficientes em suas casas". Tal questionamento, semelhante ao que relataram os demais professores desse estudo, corrobora afirmações de Mantoan (2006, 2008), Sassaki (1997), Muller e Glat (2007) e Batista (2004) de que até a década de 80 , época em que a professora Lúcia cursava o ensino fundamental e médio, não era comum ver pessoas com deficiência incluídas na sociedade; a própria família não lhes oferecia oportunidades de interagir com o meio social.

Na história de vida dos professores entrevistados, as crenças, os 
valores e as representações construídas da aula de Educação Física foram adquiridos sem a presença marcante de pessoas diferentes e com condições peculiares. Em suas vidas de estudantes nos ensinos fundamental e médio, não contaram com a presença de pessoas com deficiência que pudessem contribuir para a construção de seus saberes docentes. Tais saberes relacionados aos deficientes não teriam sido adquiridos em experiências familiares nem nas experiências escolares como estudantes.

Os primeiros contatos com o tema e com a possibilidade de atuação profissional com esse público ocorreram em disciplinas relacionadas às pessoas com deficiência na formação inicial desses profissionais, em cursos de curta duração e em estágios da área de Educação Física. Os professores desse estudo não pensavam em atuar com alunos com deficiência antes de cursar Educação Física e nem imaginavam que o curso tinha como perspectiva formar profissionais para trabalhar com atividades físicas para pessoas com deficiência. Isso acontece com muitos outros profissionais, conforme destacou Winnick (2004, p. 4):

as pessoas que seguem a carreira do ensino da educação física e do treinamento esportivo normalmente apreciam a atividade física e participam ativamente da educação física e do esporte. Entretanto, muitas vezes não tomam conhecimento da educação física e esportes adaptados até o momento em que se preparam para a carreira. Com uma consciência mais ampla, percebem que a habilidade de pessoas com necessidades especiais pode variar entre muito baixa e extremamente alta [...]. Os alunos começam a considerar que há indivíduos com diversas necessidades especiais envolvidos na educação física e esportes adaptados e aprendem também que entre pessoas com necessidades especiais há tanto portadores de deficiência como não portadores de deficiência.

Entretanto, em relação à formação inicial, apesar de ter possibilitado aos profissionais o reconhecimento da possibilidade

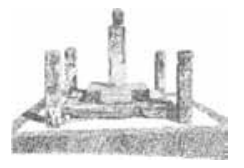


de atuação com alunos com deficiência, apenas a professora Deanne, com a experiência da formação inicial, foi tocada no sentido de escolher atuar com esse público específico. Os demais professores afirmam não terem sido influenciados pela experiência da formação inicial para trabalhar com pessoas com deficiência. Eles começaram a trabalhar no ensino especial a partir de oportunidades que surgiram após a formação em Educação Física. De acordo com a professora Deanne,

Na escola não tive, não me lembro de ter nenhum colega deficiente na escola. Tem algumas pessoas da minha família, são parentes de $2^{\circ}$ grau que são deficientes, né? Bom! Na faculdade, a pessoa que incentivava a gente a trabalhar com o deficiente foi o professor da disciplina de Educação Física para pessoas com deficiência. E é até hoje, né, pela questão da amizade que a gente tem. Gostei muito de como as disciplinas foram trabalhadas, principalmente em relação ao estágio. Aqui na escola é a supervisora, né? Pelo trabalho que ela realiza, além de todos os colegas que a gente acaba fazendo na faculdade... O Cássio, né? Que já lida com deficientes há bastante tempo, que está sempre trocando experiência. Você vê, quando acontece algum problema, a gente vai conversando, colocando algumas coisas, né, em prática. $\mathrm{O}$ que dá certo, o que não dá certo, é fazendo essa troca de experiência do dia-a-dia.

A partir de disciplinas cursadas na graduação em Educação Física, a professora Deanne teve oportunidade de conhecer entidades e escolas que atuam com diferentes tipos de deficiências, de participar de eventos esportivos e promocionais específicos para o público de deficientes e, por intermédio de um professor universitário, iniciou um estágio voluntário no Programa Superar4. Além disso, colegas de profissão mais experientes auxiliaram em

4 Programa da Secretaria Municipal Adjunta de Esportes que atua com políticas públicas de esporte destinadas às pessoas com deficiência.

Ano 13 - n. 16 - dezembro 2010 - p. 13-39 
seus primeiros passos no contexto das práticas de Educação Física no ensino especial.

Já os demais professores questionam a influência de seus cursos de formação inicial. Os professores Tenório, Daniele e Lúcia afirmaram que não receberam influências positivas para a escolha de atuar com o público de pessoas com deficiência, que as teorias desenvolvidas nas disciplinas eram totalmente desarticuladas da prática e que muitos dos professores universitários não proporcionavam vivências e contatos diretos com pessoas diferentes e com condições peculiares. Além disso, alguns desses professores não tinham interesse em atuar nessa área, como é relatado pelo professor Tenório:

Não tive muito rendimento com esta disciplina, porque na época eu não trabalhava com este público e não tinha muito interesse em trabalhar com deficiência... Na época, também, a disciplina trabalhava com várias deficiências, o conteúdo era bastante misturado. [...] Eu não tinha interesse por esta prática. A professora desenvolvia bem a teoria, dava pra entender o processo pela teoria, no entanto a questão prática ficava a desejar. As práticas eram feitas conosco mesmo, com os próprios alunos da sala; neste ponto, eu tinha dificuldade de me ver atuando com deficientes.

Como podemos ver, três professores desse estudo não se sentiram influenciados a atuar com pessoas com deficiência durante a graduação em licenciatura em Educação Física e vieram a atuar nessa área a partir de oportunidades que surgiram após a graduação. A formação continuada para atuar com públicos específicos ocorreu por intermédio de cursos obrigatórios realizados pela Secretaria Estadual de Educação, experiências e contatos com os próprios alunos com deficiência no dia-a-dia e, principalmente, com o apoio de profissionais mais experientes, como professores de diversas áreas, diretores e supervisores de escolas. É o que mostra o relato da professora Daniele:

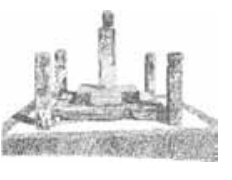


Estava dando aula no ensino regular no turno da manhã, vi um cartaz informando sobre uma designação em uma escola e me interessei; na hora que cheguei aqui, foi que fiquei sabendo que era para trabalhar com deficientes auditivos. Eu não tinha nenhuma prática, não sabia nada de Libras e, apesar da exigência de se saber Libras, eu consegui entrar na designação. Eu era a única professora formada em licenciatura em Educação Física; então a diretora sugeriu que eu assumisse a designação e fizesse paralelamente o curso de Libras. Tudo que eu aprendi foi fazendo, foi na prática. E aí eu falo que nós aprendemos somente quando praticamos.

Tal comentário nos remete às análises de Tardif (2002) e Nóvoa (2009), que ressaltam que os professores necessitam de conhecimentos específicos de sua profissão e de teorias desenvolvidas a partir da prática dessas profissões e que, portanto, a formação inicial dos professores deveria basear-se em tais conhecimentos. Os autores defendem os conhecimentos práticos e as vivências da profissão na formação inicial dos professores, além de uma reflexão do profissional que entrelace a teoria e a prática. No entanto, o que se percebe é que muitas das teorias ministradas nesses cursos são dominadas por conteúdos e lógicas disciplinares, não tendo relação com as realidades cotidianas do ofício dos professores que atuam com alunos com deficiência.

Além da necessidade de se analisar os cursos de formação inicial, os dados obtidos nos mostram a importância do conceito de formação em serviço utilizado por Mantoan (2006). A autora acredita que a formação dos profissionais não se dá apenas na graduação, mas também no convívio com alunos diferentes e com condições peculiares, em encontros de profissionais e em cursos. Portanto, é importante que se considere a formação que acontece no dia-a-dia e no trabalho direto com alunos com deficiência, o que propicia o desenvolvimento de uma série de habilidades. Grupos de discussões, encontros e debates, nessa perspectiva, são vistos 
como capazes de incentivar reflexões sobre as possibilidades de atuação em determinadas condições peculiares. Como podemos ver, Mantoan (2006 e 2008) e Tardif (2002) não consideram como formação permanente apenas os cursos práticos, mas o cotidiano escolar, as relações entre os professores, as reflexões das práticas e o convívio com os próprios alunos como elementos formativos do saber docente.

Larrosa (2002) enriquece esse debate, afirmando que o sujeito da formação é o sujeito da experiência e não da aprendizagem. $\mathrm{O}$ autor enfatiza que os saberes da experiência são o que fazem o que somos e não o que sabemos. Pelo relato da professora Deanne, as teorias das disciplinas relacionadas com deficiência no curso de graduação lhe apresentaram saberes que auxiliam sua prática, no entanto, o que lhe proporcionou formação para a prática docente foram suas experiências nos estágios das disciplinas, estágios voluntários e principalmente sua convivência com outros profissionais e pessoas com deficiência no dia-a-dia de sua atuação docente.

No estudo realizado, como vimos, os conhecimentos relacionados à prática da Educação Física escolar, adquiridos no entrelaçamento das experiências pessoais com aquelas adquiridas na formação inicial e continuada, tornam-se ferramentas fundamentais para o dia-a-dia do profissional de Educação Física que trabalha com deficientes.

\section{Concepções e práticas de Educação Física no ensino especial}

Atualmente, a formação do professor de Educação Física está pautada nos "Parâmetros Curriculares Nacionais" (PCN), publicados a partir de 1997. Esses parâmetros tiveram como principais referências em sua formulação as abordagens da psicomotricidade crítico-superadora, desenvolvimentista e construtivista que influenciaram a elaboração de conteúdos da "cultura corporal do movimento" a serem desenvolvidos nas

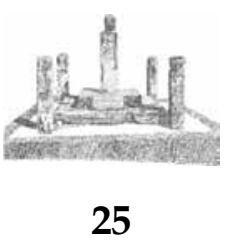


aulas de Educação Física.

A professora Deanne parece se orientar por tais concepções, já que acredita que os conteúdos da Educação Física a serem trabalhados na escola estão relacionados com as práticas culturais que envolvem o movimento corporal - práticas constituídas pelos esportes, danças e expressões corporais. Em relação aos esportes, a professora enfatiza a importância de se trabalhar as habilidades e as regras das modalidades e de se estimular os alunos a participar das atividades de forma autônoma, com o mínimo de dependência possível.

Para que os alunos com deficiência consigam realizar as atividades de forma autônoma, de acordo com Deanne, um dos objetivos principais do trabalho da Educação Física é desenvolver a coordenação motora. Os conteúdos observados em suas aulas, bem como os objetivos da Educação Física, estavam de acordo com as propostas dos Parâmetros Curriculares Nacionais e com os elementos da cultura corporal do movimento (SOARES et al., 1992). Em relação aos objetivos propostos pela Educação Física escolar, a professora afirma:

[...] pelo público que a gente atende aqui na escola, pra mim, a prioridade é a coordenação motora, porque os meninos chegam muito limitados mesmo, não sabem pular uma linha, uma corda. A prioridade para eles... eu acredito que seja a coordenação motora, para depois se iniciar um esporte, ser iniciado... A gente tem alguns alunos aqui na escola que não conseguem se deslocar se não tiverem um auxílio, né? Sem este auxílio pra andar fica muito difícil pra ele realizar o movimento do corpo mesmo.

Concepções e posturas diferentes foram observadas nas falas da professora Daniele, que acredita que a única diferença da Educação Física em relação ao ensino regular comum é o número reduzido de alunos. No caso de turmas em que tenham alunos com deficiências múltiplas, ela afirma trabalhar basicamente com a coordenação motora. Interessante que esse discurso é recorrente 
a todos os professores desse estudo, que sempre enfatizam a importância da coordenação motora e da psicomotricidade no trabalho com turmas com alunos deficientes mais comprometidos.

O professor Tenório destaca como conteúdos que devem ser trabalhados com alunos com deficiência visual a expressão corporal, a psicomotricidade, a lateralidade, os movimentos corporais a partir da música e os movimentos fundamentais. Além disso, em sua perspectiva de atuação com deficientes visuais, o professor deve utilizar vários materiais, principalmente para o reconhecimento dos alunos, tais como pneus, bambolês, cordas e bolas de diferentes tamanhos. Durante as observações das aulas, pôde-se perceber muitas dificuldades desse professor em desenvolver certos conteúdos; entre eles, a de demonstrar movimentos novos aos alunos e realizar estímulos como, por exemplo, o uso de sons, tato e práticas guiadas pela informação verbal e pelos movimentos cinestésicos, isto é, movimentos realizados pelos alunos com o auxílio do professor. O conteúdo que Tenório mais trabalhava com os alunos eram os movimentos fundamentais básicos, isto é, andar, correr, agachar, segurar em algo e saltar, além de atividades culturais em roda. Ele relatou, durante as observações das aulas, sua dificuldade de trabalhar esportes com os alunos, em função de desconhecer os praticados por pessoas com deficiência visual.

Atualmente, os deficientes visuais praticam várias modalidades esportivas; entre as principais estão o goalball, futebol de cinco, judô, natação, atletismo e xadrez. Existe em Belo Horizonte uma associação de deficientes visuais que fomenta esportes para esse público. O relato do professor nos mostra uma lacuna na formação dos profissionais que atuam com deficientes, que reflete sobretudo naqueles que estão em início de carreira.

Em relação aos conteúdos desenvolvidos com os alunos, a professora Lúcia dá ênfase aos esportes e aos pequenos jogos, atividades que envolvem o lúdico, pois, segundo ela, oferecem mais possibilidades de execução por parte dos alunos. Nesse sentido, afirma:

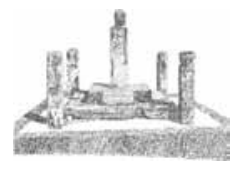


Trabalho todas as modalidades, movimentos básicos, o lúdico, nada com muita exigência, mas com muitas brincadeiras e sempre incentivando os alunos a fazerem a aula... apesar da escola não ter uma estrutura que me permita desenvolver muitas modalidades... Agora, tem que ver também o que os alunos dão conta de fazer, o que eles conseguem fazer em razão da memória deles.

Podemos perceber nos discursos dos professores pesquisados um conhecimento sobre os conteúdos propostos pelos Parâmetros Curriculares Nacionais da Educação Física. No decorrer das aulas, foram observados conteúdos relacionados aos esportes, ginásticas, atividades rítmicas e expressivas e pequenos jogos. No entanto, apesar de aparecerem no discurso de alguns professores, não foram observadas propostas de interdisciplinaridade e nem reflexões voltadas aos temas transversais, que estão previstas nos PCN.

Para a consecução dos objetivos propostos nas aulas de Educação Física, a professora Deanne afirma que utiliza como avaliação as observações e anotações dos desempenhos dos alunos nas aulas. Informa que essas anotações são da ordem quantitativa, com obtenções de tempos, participações em jogos e registros de desempenhos, e qualitativa, com observações sobre a participação e o envolvimento dos alunos com a Educação Física e os demais colegas. Deanne ressalta que as observações sobre o comportamento dos alunos, além dos objetivos inerentes à Educação Física, são necessárias em função de medicamentos que os alunos utilizam e que modificam a forma como interagem com o meio social. De acordo com a professora, em função dessa avaliação qualitativa, ela estabelece um diálogo com a direção e com os familiares. Esses comportamentos diferenciados se manifestam muito na aula de Educação Física, em função de ser um espaço mais aberto e livre para as expressões comportamentais dos alunos. Segundo Deanne, a avaliação é realizada de forma processual, sem uma perspectiva hierárquica entre os próprios alunos e com uma proposta de que cada um tenha seu ritmo de aprendizado. 
Em relação a esse aspecto, os professores Tenório, Lúcia e Daniele informaram que não existe uma avaliação sistematizada do aluno na aula de Educação Física. Segundo eles, a avaliação é realizada por meio de observações individuais ou do comportamento do aluno na turma. Parece haver, no discurso dos professores entrevistados, indícios de dificuldades em se avaliar as potencialidades dos alunos.

Mantoan (2006), ao discutir sobre o processo de avaliação, enfatiza sobre a importância de explorar talentos, atualizar possibilidades e desenvolver predisposições naturais de cada um dos alunos. Nesse sentido, a avaliação sistematizada, processual, individualizada, não hierárquica e a perspectiva de detectar as possibilidades do aluno ganha importância no trabalho com alunos com deficiência. Inclusive, para se estruturar um planejamento, a avaliação das potencialidades dos alunos deveria estar estabelecida.

Tanto durante as observações das aulas quanto nas entrevistas não foram mencionados pelos professores dificuldades inerentes aos alunos. Apesar de serem alunos com deficiências múltiplas, de estarem em turmas heterogêneas e apresentarem quadros de mudanças de comportamento, em nenhum momento isso apareceu como dificuldade nos relatos. No entanto, de acordo com Aguiar (2005), Araújo (1999), Bueno (2004), Carvalho (1998, 2007), Glat (2007), Mantoan (2006, 2008) e Sassaki (1997), para os professores do ensino comum regular, questões referentes aos alunos com deficiência apresentam-se como dificuldades, tais como a falta de formação para atuar com deficientes, a heterogeneidade das turmas e o desinteresse em atuar com o público de deficientes.

Tendo em vista que o ambiente educacional pode propiciar meios para viabilizar e facilitar o processo de inclusão, os aspectos citados acima nos levam a refletir sobre o papel da Educação Física na escola, bem como sobre a ação educativa do professor. Pode-se considerar que a participação efetiva e a ação do professor parecem influenciar diretamente a função pedagógica que a Educação Física deve assumir na escola, o que implica um novo

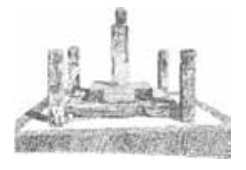


olhar para a inclusão.

\section{Olhar dos profissionais sobre a inclusão}

A inclusão de alunos com deficiência no sistema regular de ensino e, consequentemente, a formação dos professores para atuar com tal público têm sido, sem dúvida, as questões referentes à educação mais discutidas em nosso país nas últimas décadas. Atualmente, além de estarem presentes em congressos, cursos de capacitação e textos da literatura especializada, são objetos de propostas de intervenção em legislações e em políticas públicas educacionais em níveis federal, estadual e municipal.

O papel da Educação Física no processo de inclusão dos alunos com deficiência, de acordo com a professora Deanne, é o de "dar oportunidade para todos pra experimentar de tudo". De acordo com a professora, na Educação Física os alunos têm a possibilidade de vivenciar atividades que não são vivenciadas no seu dia-a-dia, tais como dançar, jogar futebol, praticar atletismo, jogar bocha, fazer ginástica e participar, por exemplo, de uma aula cujo conteúdo seja o circo. Em relação a essa questão, a professora comenta:

[...] tento proporcionar a maior diversidade de temas para que esse aluno possa participar de tudo, né? Porque, muitas vezes, lá fora, num outro espaço, ele não vai ter essa oportunidade! Vivenciar um pouquinho de cada coisa... de cada coisa. Por exemplo: se tiver um dia aí que o tema da aula seja circo, vai ter aquele momento, porque a gente não sabe se a família vai ter condições, por exemplo, de levá-lo pro circo, né? Então, é vivenciar todos os temas dentro da escola, porque a gente não sabe se ele vai vivenciar isso fora.

Para Deanne e Tenório, além de propiciar vivências aos alunos de atividades que não realizariam fora do ambiente escolar, a Educação Física permite a socialização entre eles próprios, entre seus familiares e pessoas que não estão inseridas no contexto da 
escola especial.

Segundo Tenório, o principal papel do professor de Educação Física no processo de inclusão na aula de Educação Física é estimular os alunos a fazerem atividades físicas. De acordo com ele, uma das grandes dificuldades dos alunos fora do ambiente escolar diz respeito à socialização; por isso acredita que é importante estimular, desenvolver condutas que facilitem a socialização e proporcionar autonomia e independência dos alunos com deficiência visual, principalmente no sentido da orientação espacial e da mobilidade. Para Tenório, esses seriam os principais objetivos da Educação Física no trabalho com esse público específico.

De acordo com o relato de Daniele, "não é difícil incluir a pessoa com deficiência auditiva na sociedade". A professora afirma que eles já estão sendo incluídos na sociedade e mesmo no trabalho, com a contratação de deficientes em empresas, ou mesmo no ambiente escolar, por intermédio da política de "escola para todos". No entanto, segundo Daniele, o grupo de pessoas com deficiência auditiva é fechado, prefere estar junto e gosta de se comunicar apenas por Libras: "Se existe um ouvinte que não sabe a Libras, os deficientes auditivos não se aproximam, não tentam se comunicar por outra maneira". Por isso considera o conhecimento de Libras por parte dos professores, funcionários e mesmo dos alunos como de fundamental importância para a inclusão dos alunos com deficiência auditiva na escola.

Em relação às aulas de Educação Física, a professora considera muito fácil incluir o deficiente auditivo, pois "as crianças com deficiência auditiva já brincam com as crianças ouvintes no seu dia-a-dia e a única dificuldade realmente é a audição, já que elas são capazes de realizar tudo que envolva o movimento". Para Daniele, em relação às outras disciplinas, os alunos com deficiência auditiva têm muitas dificuldades em estar inseridos na "escola para todos". Nas "escolas para todos", segundo Daniele, os professores não sabem Libras, têm dificuldades de ensinar conceitos abstratos aos alunos e, apesar da obrigatoriedade do intérprete na sala de

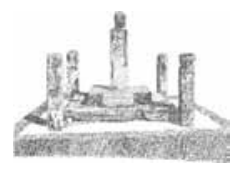


aula, muitos alunos com deficiência auditiva não dão conta de acompanhar o ensino, param de estudar ou retornam ao ensino especial. Segundo ela, tais problemas representam uma barreira para a inclusão e para a conquista de uma "escola para todos".

De acordo com Lúcia, apesar de ser obrigação dos professores atenderem a todos os alunos, independentemente de suas diferenças, não são todos que aceitam trabalhar com alunos com deficiência. Por não receberem formação adequada para atuar com esse público específico, afirma que, muitas vezes, de forma velada, os professores prejudicam ainda mais o desenvolvimento desses alunos. Em seu discurso, a professora critica as políticas públicas de educação, que não oferecem condições de formação para os docentes e nem preparam a escola regular comum para receber alunos com deficiência: "Os alunos estão indo para o ensino regular sem uma preparação da escola".

Considerando as abordagens aqui apresentadas, podemos observar que a Educação Física no ambiente escolar vem buscando uma transformação e melhor compreensão de seu papel na perspectiva de ampliar a participação da população escolar nas atividades desenvolvidas pela disciplina. Nesse sentido, a Educação Física, num processo histórico, vem se transformando para atender a todos, independentemente das necessidades especiais do aluno.

\section{Considerações finais}

Nas últimas décadas tem-se observado um grande número de documentos, leis, políticas públicas e planos estratégicos com a perspectiva de melhorar a qualidade do ensino, em consonância com práticas educativas comprometidas com a diversidade cultural e com a construção de uma sociedade justa, inclusiva e democrática. No entanto, sabemos que as transformações no ensino passam pelos professores e que é preciso ouvi-los para avaliar em que medida as intenções das políticas públicas estão 
sendo realmente implementadas na prática cotidiana das escolas. É preciso, pois, conforme destacaram Tardif (2002), Nóvoa (1992, 1995 e 2009), Muller e Glat (2007), analisar as práticas docentes e ouvir os professores atuantes no cotidiano escolar, especialmente no que diz respeito aos novos desafios colocados pelas políticas públicas de formação de professores para o ensino com deficientes.

A respeito da formação inicial, embora essa experiência tenha se destacado apenas em uma das entrevistas realizadas, chama a atenção o fato de que uma das professoras afirma ter sido influenciada a trabalhar com alunos com deficiência a partir do conhecimento de disciplinas que abordavam o tema "Educação Física e atividade física para pessoas com deficiência" no curso de graduação. Apesar de entender que seu saber docente vem sendo adquirido diariamente com sua prática, considerou importante, para dar início à sua profissão, o conhecimento teórico e prático adquirido no curso de Educação Física. A professora enfatiza que, por intermédio de vivências teóricas e práticas, relacionamentos positivos com o professor universitário, bem como interferências de professores de Educação Física mais experientes, sentiuse tocada a atuar com esse público. Além disso, seu curso de licenciatura em Educação Física oferecia uma boa carga horária em relação a esse conteúdo específico; havia também vivências e estágios em práticas esportivas para pessoas com deficiência e a teoria apresentava relação direta com a prática docente. Estas experiências auxiliaram sua escolha em trabalhar com pessoas com deficiência, influenciando também sua constante busca por cursos de capacitação profissional e envolvimento na área do público de deficientes.

Por outro lado, os demais professores entrevistados não especificaram influências significativas da formação inicial para a escolha de atuar com o público de pessoas com deficiência. Eles relataram que os conhecimentos adquiridos na graduação para atuar com o referido público não foram suficientes, mencionando a carga horária reduzida e as dificuldades de relacionar teoria e

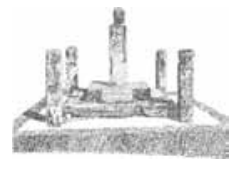


prática. Foi citada também a dificuldade de alguns professores universitários em ministrarem conteúdos práticos relacionados a alunos deficientes. No entanto, a experiência positiva de uma das professoras no curso de graduação, como citado anteriormente, mostra-nos que os cursos de licenciatura em Educação Física poderiam contribuir para a formação de professores mais sensibilizados com os temas da inclusão e da deficiência.

Os professores entrevistados ressaltaram que, ao iniciarem suas carreiras como docentes, não estavam confiantes quanto às suas capacidades para atuar com deficientes. Apesar dos conhecimentos adquiridos na formação inicial, muitas demandas em relação aos saberes docentes surgiram a partir da prática e do convívio com os alunos no cotidiano escolar. Para enfrentar tais desafios, recorreram à ajuda de colegas mais experientes em busca de apoio, muitos deles não vinculados à área da Educação Física, e à aquisição de conhecimentos a partir das suas próprias experiências. Entretanto, na maioria das vezes, a colaboração dos colegas mais experientes se dá informalmente, sendo que poderia ser uma política de formação continuada.

Vimos nas entrevistas e nas observações da prática dos professores desse estudo, provavelmente pelo fato de estarem situados em ambientes que atuam diretamente com alunos com deficiência, que estão realizando investimentos pessoais e profissionais em formação para atender a esse público. Vêm buscando participar, muitas vezes por conta própria, de cursos diversos de formação continuada: Libras, Braille, cursos obrigatórios da Secretaria Estadual da Educação e cursos práticos de curto prazo e de especialização. Dessa forma, procuram aprimorar sua prática docente, com retorno visível para os alunos no sentido de auxiliar sua convivência social e propiciar benefícios físicos. De acordo com Mantoan (2006, 2008), Batista (2004), Carvalho (1998, 2007), Rodrigues (2006), Pedrinelli (2005), Sassaki (1997), entre outros autores, isso não acontece com pessoas que estão se formando em licenciaturas e atuando no ensino regular comum. 
Entretanto, em relação à inclusão escolar de todos e ao respeito às diferenças e diversidades, ainda há muito a ser transformado nas escolas, tanto do sistema de ensino especial quanto do sistema regular comum. Transformações que dependem de políticas públicas de educação voltadas para a melhoria da formação inicial e continuada dos professores e da estrutura física e pedagógica das escolas, assim como de novas atitudes dos profissionais, no sentido de entenderem e considerarem as diversidades.

Por fim, a pesquisa realizada não teve como pretensão ser conclusiva, mas trazer à tona questões que envolvem a formação e a prática de professores de Educação Física em trabalhos com alunos com deficiência. Os desafios para superar e conviver com as diferenças são muitos e, por mais adversas que se apresentem as condições de trabalho, torna-se importante refletir sobre as possibilidades de formação do saber docente, bem como de melhorias para uma prática de qualidade. Portanto, novos nichos de pesquisa apontam para dar continuidade a estudos sobre essa temática, com novas possibilidades de investigação e amostra de professores. 


\section{Referências}

AGUIAR, J. S.; DUARTE, E. Educação inclusiva: um estudo na área da Educação Física. Revista brasileira de Educação Especial, Marília, v. 11, n. 2, p. 223-240, 2005.

ARAÚJO, P. F. de. A educação física para pessoas portadoras de deficiências nas instituições especializadas de Campinas. Campinas: Editora da Unicamp, 1999.

BARDIN, L. Análise de conteúdo. Lisboa: Edições 70, 1977.

BONDÍA, L. Jorge. Notas sobre a experiência e o saber da experiência. Revista Brasileira de Educação, Rio de Janeiro, n.19, p. 20-28, jan./abr. 2002.

BRASIL. Lei n. 9394, de 20 de dezembro de 1996. Fixa as Diretrizes e Bases da Educação Nacional. Brasília: Diário Oficial, n. 248, de 23/12/1996.

Ministério da Educação e do Desporto. Parâmetros Curriculares Nacionais - Ensino Fundamental - Educação Física. Brasília: Secretaria de Educação Fundamental, 1997.

Ministério da Educação e do Desporto. Parâmetros Curriculares Nacionais - Terceiro e Quarto Ciclos do Ensino Fundamental - (Introdução aos Parâmetros Curriculares Nacionais). Brasília: Secretaria de Educação Fundamental, 1998.

Ministério da Educação e do Desporto. Parâmetros Curriculares Nacionais - Ensino Médio / Secretaria de Ensino Médio. Brasília: MEC/SEM, 1999.

CARVALHO, R. E. A nova LDB e a Educação Especial. 4. ed. revisada e atualizada. Rio de Janeiro: WVA, 2007. 
FRANCO, M. L. P. B. Análise do Conteúdo. 3. ed. Brasília: Líber Livro, 2008.

GLAT, R. Educação Inclusiva: cultura e cotidiano escolar. Rio de Janeiro: 7 Letras, 2007.

GORGATTI, M. G.; COSTA, R. F. Atividade Física Adaptada: qualidade de vida para pessoas com necessidades especiais. São Paulo: Manole, 2005.

MANTOAN, M. T. E. Inclusão escolar: o que é? Por quê? Como Fazer? São Paulo: Moderna, 2006. . O desafio das diferenças nas escolas. Petrópolis: Vozes, 2008.

MULLER, T. M. P.; GLAT, R. Uma professora muito especial. Rio de Janeiro: 7 Letras, 2007.

NÓVOA, A. (Org.). Os professores e a sua formação. Lisboa: Dom Quixote, 1992. . Vidas de professores. Porto: Porto Editora, 1995.

. Professores: imagens do futuro presente. Lisboa: EDUCA - Instituto de Educação Universidade de Lisboa, 2009.

PEDRINELLI, V. J. Educação Física Adaptada a serviço das diferenças: atual panorama na América do Sul. Revista Sobama, Rio Claro, v. 7, n. 1, p. 45-51, 2002.

PEDRINELLI, V. J.; VERENGUER, R. de C. G. Educação Física Adaptada: introdução ao universo das possibilidades. In: GORGATTI, M. G.; COSTA, R. F. Atividade Física Adaptada: qualidade de vida para pessoas com necessidades especiais. São Paulo: Manole, 2005, p. 1-27.

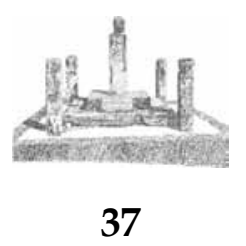


RODRIGUES, D. Atividade Motora Adaptada: a alegria do corpo. São Paulo: Artes Médicas, 2006.

SASSAKI, R. D. Inclusão - construindo uma sociedade para todos. Rio de Janeiro: WVA, 1997.

SOARES, C. L. et al. Metodologia do ensino da Educação Física. São Paulo: Cortez, 1992.

TARDIF, M. Saberes docentes e formação profissional. Petrópolis: Vozes, 2002.

WINNICK, J. P. Educação Física e Esportes Adaptados. Tradução da 3. ed. original de LOPES, F. A. Barueri: Manole, 2004. 


\title{
Influence of training in the practice of Physical Education teachers who work with students with disabilities: a study in the special education system
}

\begin{abstract}
This article synthesizes some results from a survey that aimed to identify the influences of training in the practice of physical education teachers who work with disabled students in special education. The research included the participation of four physical education teachers from three public schools special education, administered by the state of Minas Gerais, located in Belo Horizonte. Data were collected through semi-structured interviews, participant observation of teaching practices and document analysis. The results showed that despite the progress made, much remains to be done towards the improvement of initial and continuing training of teachers, with a view to education committed to diversity and inclusion for all, especially students with disabilities. In this direction, the study indicated the potential formation of knowledge acquired in the direct experience with disabled students and networks of exchange and support with more experienced professionals.
\end{abstract}

Keywords: Physical Education; teacher training; students with disabilities; special education.

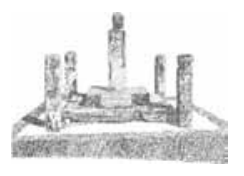

